\title{
GOOD/BAD, RIGHT/WRONG, AND THEIR ANALOGUES
}

\section{BUENO/MALO, CORRECTO/INCORRECTO Y SUS ANÁLOGOS}

\begin{abstract}
This essay presents an experimental theory of values. An abstract schema is extracted from two pairs of concepts that are used in moral evaluation, good and bad, on the one hand, and right and wrong on the other. The schema is then used to explore the analogues of the moral concepts in aesthetic and epistemic evaluation.
\end{abstract}

Keywords: Moral. Aesthetic and Epistemic Value. Experience and Behavior.

\begin{abstract}
Resumen: Este ensayo presenta una teoría experimental de los valores. Se extrae un esquema de dos pares de conceptos que se utilizan en la evaluación moral: bueno y malo, por un lado, y correcto e incorrecto por el otro. El esquema se usa luego para explorar los análogos de los conceptos morales en la evaluación estética y epistémica.
\end{abstract}

Palabras clave: Moral. Valor estético y epistémico. Experiencia y Comportamiento.

As for willing, it is equally plausible that it is justified by valuing. If one were asked why one wanted genocide and the raping of babies stopped and prevented in all possible ways, the answer would probably begin with the assertion that such things are evil, that is, extremely negatively valued actions on animate beings. However, this question is only a beginning since few philosophers would fail to find that another question immediately arises: namely, the question of what justifies this negative valuing [...] One might contend that it is once again evidencing that justifies valuing. ${ }^{1}$

In the passage above, Lester Embree asks a question and a gives hint at the answer. Below, in the first part about moral evaluation I say some things that

${ }^{1}$ Lester Embree, "Extremely Bad Things: Some Reflective Analysis of Valuation", in Lester Embree \& Michael Barber, The Golden Age of Phenomenology at the New School for Social Research, 1954-1973 (Athens: Ohio University Press, 2017), pp. $319 f$. 
elaborate his answer. My overall intention here is to go beyond moral evaluation and to present a schema for exploring some similarities between the moral and two other areas of evaluation, the epistemic and the aesthetic, and to begin that exploration.

I will first take two sets of terms that are common in moral evaluation and use them in a way to form two distinct and related dimensions of evaluation, from which I will then extract an abstract framework of relationships (hereafter referred to as the "schema") and apply that to the two other areas. I will explore the implications and advantages of this framework in all three of the value areas. It is in these implications and advantages where I see the merits of the schema, and I offer these merits as support for the schema. So, in setting out the ideas about moral evaluation, I will give stipulative definitions and will not be claiming that the concepts tell the truth about moral evaluation.

\section{MORAL EVALUATION}

"Good" and "bad", "right" and "wrong" are terms commonly used in moral evaluation ${ }^{2}$. They have various meanings, however. For example, sometimes "right" and "good" are used synonymously and sometimes they are used with different meanings. I am going to use these terms to name four distinct concepts. In order to do so, I will pick four distinct meanings that these terms have had and further specify those meanings in a particular way.

"Good" and "bad" are terms that are used to express positive and negative moral value. I will use them exclusively to evaluate objects and states of affairs that come about by human action, and not, as is sometimes done, to judge a person because of what they do, or to judge an action that a person performs. So, for example, if a person does something that causes the death of another person, they have brought about something that has negative moral value, something "bad". We can then say to the person "you did something bad", but not "your doing that was bad", or "you are a bad person". Also, in the way I am using the terms "good" and "bad", they express the value of something because of what it is, and not because of its relation to anything else. They are intrinsic values. This means that the value is independent of anything about or

\footnotetext{
${ }^{2}$ Here and below I will be using only two terms for the positive and negative values, not meaning to imply that there are not shades of value and many terms.
} 
surrounding the action that brought it about. In our example, the death is bad regardless of the circumstances in which the act causing it was performed, or the intention of the actor in performing the act, or any other matter concerning the person or action. On the other hand, if someone saves a person who otherwise would be murdered, they have brought about a "good" result, regardless of such things as the actual intentions of the person doing the saving, the identity of the person saved, etc.

Whereas "good" and "bad" concern what is brought about by a person's action, the terms "right" and "wrong", express the positive or negative value of the action, i.e. the person's bringing about of the state of affairs. These values are not intrinsic to an action but depend on various kinds of factors outside of the action itself such as the circumstances in which the act was performed, the intention of the actor in performing it, the identity of any person who is affected by the action, etc... So, for example, while it is bad to bring about the death of a person, it could be considered "right" if that person was Adolf Hitler during the early 1940's.

Now, right and good "line up", as do wrong and bad, for normally it is right to perform an act that brings about a result having positive moral value and wrong to perform one that brings about a result with negative moral value: "do good; avoid evil". They line up because the positive or negative moral value of the state of affairs brought about by an action bestows it's moral value on the act that brought it about. But this bestowal does not go the other way, from the value of the action to the value of the state of affairs brought about by it. Because good and bad are intrinsic features of a state of affairs, the rightness or wrongness of an act does not affect its moral value. If in a particular case it is right to do something bad, the rightness does not affect the badness of the result, as in the case of the example of Hitler. It stays bad. Similarly if it is wrong to do something good, the wrongness in the first case does not affect the goodness of the result, which stays good. These are what I will call "crossover" cases, which I will now discuss.

"Crossover cases" are cases where right and good, wrong and bad do not line up. It is where "right" goes with "bad", and where "wrong" goes with "good". In these crossover cases, such things as the circumstances in which an act was performed, the intentions of the person in performing it, or the identity of the recipient of the action, can act to outweigh the value coming from the result and 
thus justify an evaluation that is the opposite of that value. An action that produces a state of affairs that has negative moral value can then be "right". It would be "right" because the performance of the act was justified; the reasons for performing the act outweighed the negative moral value that the result bestows on the act. Likewise, an act that produces something of positive value could be wrong if factors were present that outweighed the positive value emanating from the resulting state of affairs. Let me explain and elaborate more by using an example.

First I will present a case where the values line up. When I was a high school teenager I had a friend who hunted animals. His family had guns and a hunting dog. One day he invited me to go with him to hunt rabbits. This was the first time I ever went hunting. He loaned me a double barrel shotgun. We were standing in a clearing surrounded by woods when the dog chased a rabbit in front of me, about 50 feet away. I aimed and pulled the trigger. The rabbit was hit and flew up in the air and then down on its back where it was moving its legs as if struggling for its life. I became overcome with emotion seeing this; I was frightened and I wanted the movement to stop immediately, so I shot again and the movement stopped. Then a thought came to me: "Bill, you have just messed around with something (life) that you should not be messing with". Here the bad result and the wrongness line up.

Now I will present a crossover case. This is a case, reported years ago in the newspapers, of an elderly man, Woody Collums, who shot and killed his brother who was suffering from dementia. Quoting from a news article, the brother

lay helpless in his bed at a nursing home, his brain cells degenerating, unable to speak or to care for himself, kept alive by nutrients flowing through a tube that ran through his nose and into his stomach as he slid inexorably toward death. That is when Woody Collums says he took matters into his own hands. "I just couldn't leave him like that", he said later in a quavering voice. So, after a moment's indecision, he pumped three .38-caliber pistol shots into his abdomen, "just as fast as I could".... Mr. Collums says he has no regrets and would "absolutely" do it again "to get him out of his misery". ${ }^{3}$

${ }^{3}$ The New York Times, 12/10/1981. 
Mr. Collums was indicted for his act and pleaded guilty. At one of his legal hearings he said "I regret having to do what I did, but I don't regret doing it"4.

In terms of the concepts I am using here, Mr. Collums thought that it was right to do what he did, because it was justified, and he recognized that what he did was something bad.

There are two things about this story and the one about me and the rabbit that will help me clarify further and advance the ideas I am presenting. First, in my story the badness is experienced by an emotion, the fear I felt. I think that the same was involved in the case of Woody Collums. I understand his shooting "just as fast as I could" to be like my shooting to stop the rabbit's movement "immediately". Both were attempts to limit negative emotion, in my case the emotion that I was feeling, and in his case an emotion that he knew he would be about to feel. In the theory I am presenting, feeling and emotion are the primary ways of experiencing value. This does not mean that everyone, or someone on every occasion, will experience value in this way, but I think that the value aspect of the world is originally experienced by feeling and emotion. It is appropriate to have a negative emotion if the consequences of one's act are bad, even if performing the act is right. The scheme validates this, and I think this is one of its advantages. What if one does not have such feelings? You do things that have bad results and you feel nothing, for example. Well, this is not appropriate. The scheme points to the need for education in moral perception. We know that in many areas of experience, one needs to learn how to perceive what is there. Experiencing food and wine are examples of this that most people are familiar with, where some training is needed to detect flavors. We would have to develop ways of sensitizing people to the bad and the good. In many cases, of course, this seems to come naturally. When I was a young child, someone in my family accused me of doing something I did not do. This was the first time this happened to me and I was spontaneously overcome by a feeling of being offended and, because of this feeling, I said to myself "I will never do that to anyone". Soldiers in war know all about feeling and emotion in experiencing the bad.

Second, and this is apparent in Woody Collums's story, there is no need to feel guilt after performing an act that has bad consequences but is the right thing to do, or no need to think you are a hypocrite for recognizing the badness and

\footnotetext{
${ }^{4}$ The New York Times, 02/06/1982.
} 
not feeling guilt. In saying "I regret having to do what I did, but I don't regret doing it", Mr. Collums showed that he understood what I take to be an important implication of the independence in the crossover cases, namely, that the rightness of an action does not affect any badness of its result. It stays bad, and "regret" is a feeling that is called for in cases like this. One advantage of the feeling of regret is that it promotes caution and circumspection in doing things that bring about bad results. The same advantage of caution and circumspection is true in a different way in the second kind of crossover case, where a good result comes about through a wrong action. I will leave it to the reader to think of an example of this and to determine where the "regret" should be aimed.

Another advantage of the ideas that I am presenting is that they may help settle or at least clarify some disputes about morality. To take a new example, let us say that in certain cases the result of having an abortion is bad; it ends a "human life". But there may be reasons that justify having an abortion and thus make it right. I think that in some disputes about abortion the side that wants to forbid it is focused on the badness of the result and the other side is focused on the rightness-but neither side realizes that they are focused on separate things that require, according to my scheme, separate discussions. In some disputes about a particular abortion one side that is emphasizing the badness of the result may be thinking that it forbids the act. The other side may emphasize the rightness of having the abortion, thinking that this takes away the badness of the result. They would be deadlocked. Disputes like these can at least be clarified if both sides adopt the scheme I am proposing. Then the disputes will no longer be so intransigent. If both adopt the account of the crossover cases, both can agree about the badness, and then turn to arguing about the justification. Both can feel regret that the abortion had to be done, an appropriate feeling that can prevent unjustified acts, but not one that changes how one thinks about the rightness of the act.

To sum up where we are thus far in abstract terms, I have presented a schema for evaluating value that has four components:

1) Some objects or state of affairs that can have intrinsic positive or negative value properties;

2) A way that a person can experience the value properties;

3) A way that a person is dynamically related to the object or state of affairs; 
4) Positive and negative judgments of the way of being related.

The scheme has two pairs of evaluative concepts, one pair for the value properties of the object or state of affairs, and another pair for the evaluation of the way the person is dynamically related to these.

Now comes the more exploratory part of this paper. Here I invite the reader to participate in applying this scheme in an experimental way to two other value areas, the aesthetic and the epistemic (another area of application could be the practical-with useful/useless). We will use the schema above and try to identify the analogues of the different items.

\section{Aesthetic EVALUATION}

Some objects or states of affairs that can have intrinsic positive or negative value properties:

It would seem that the analogues of good and bad, in the case of fine art, are beautiful and ugly. For music we need a different term for negative value because "ugly" does not fit. "Bad" is often used".

A way that a person can experience the value properties:

Various forms of aesthetic feeling would be the way that a person would experience the aesthetic value of something, for instance, the feeling of awe in seeing a beautiful natural landscape, or of disgust when encountering a very ugly person.

A way that a person is dynamically related to the object or state of affairs:

The analogues in the aesthetic sphere of a person's action in the moral sphere (do good, avoid evil) would seem to be various kinds of attraction ("move towards") and repulsion ("move away from"). I have an example from my own life. I am in my study reading and writing and some classical music is playing on the radio in the background. As I concentrate on my work, some unusually beautiful music keeps calling my attention and eventually I stop what I am doing 
and turn my attention toward it and stay fixated on it (it was Beniamino Gigli singing "Mamma"). Or, on another occasion, some music that is annoying me intrudes on my attention and I cannot stand it, so I get up and turn off the radio.

Positive and negative judgments of the way of being related:

In the cases above, things "line up". What words shall we use to name the judgments that are analogous to right and wrong in the moral sphere? We need to fill in this formula: It is ' $X$ ' to move towards the beautiful", and ' $Y$ ' to move away from the ugly. $X$ is perhaps "tasteful", where "tasteful" means "showing good aesthetic judgment or appropriate behavior"6. And $Y$ ?

What about crossover cases. Here is where things get interesting to think about, as we will be on unchartered territory. We seek terms that express evaluations where the context provides something analogous to justification for what otherwise would be an incorrect evaluation. For example, suppose someone is attracted, rather than repulsed, by a person who is extremely ugly. Where things line up we would say "it is perverse to be attracted toward the ugly", where "perverse" would be the analogue of "wrong". But this would be an incorrect evaluation if the context provided overriding justification for the behavior. What might justify moving one's attention toward a person with a physical deformity that makes them ugly? Or the same question about the posture of the slain on the battlefield in war. In the case of moral evaluation, justification as discussed above consisted of positive factors outweighing (but not cancelling) the negativity emanating from the bad. What would be analogous to this in the case of aesthetic evaluation? Perhaps this: the moving toward of one's attention could take the form of a certain fascination with the unusualness and uniqueness of the configuration of the ugly. The analogue of "right" here could be "generous", and the person exhibiting this willingness to see something positive in something that nonetheless remains ugly, could say (analogous to expressing regret): I don't apologize for my fascination, but I do regret the way it risks validating the ugliness.

\footnotetext{
${ }^{6}$ See https://www.google.com/search?safe=active\&source=hp\&ei=Fe4NWvDWG4rKmwHzi5iwBg\&q=tasteful\&oq=tasteful\&gs $I=$ psy-ab.1.1.0i131 k1j0l9.1452.3863.0.6600.8.8.0.0.0.0.111.710.7j1.8.0...0 ...1.1.64.psyab..0.8.707...0. kxxNE8naWIU
} 
Here too, I will leave it up to the reader to think of the other kind of crossover case, where a negative evaluation would be justified for an attraction to something beautiful.

\section{EPISTEMIC EVALUATION}

Something that can have intrinsic positive or negative value properties:

Within the knowledge sphere it is statements that have value, as true or false, which are then the analogues of good and bad. Can we say, though, that truth and falsity are intrinsic properties of statements? After all, one theory has it that the truth or falsity comes to a statement from its "correspondence with reality", and so is dependent on something outside of itself (at least in the case of many types of statements). While this seems to make these value properties different from the previous ones, there is nonetheless enough independence from some other factors to make applying my schema to epistemic value an interesting discussion, other factors such as the strength of someone's belief in a statement, the statement's relation to other statements, the authoritative status of someone who endorses the statement, or the value that belief in the statement may have for the person who believes it.

A way that a person can experience the value properties:

People have an original experience of truth and falsity when they reflect on the experiences of confirmation and disconfirmation of beliefs that they have (working here with the Correspondence Concept of truth).

A way that a person is dynamically related to the object or state of affairs:

This would be believing or disbelieving the statement. To believe a statement is to relate oneself to it in a giving of assent to it and to disbelieve it is to reject it.

Positive and negative judgments of the way of being related:

"Rational" and "irrational" would be terms that can be used to evaluate believing. These are the counterparts of right and wrong.

In the cases where the values line up, it is rational to believe what you know to be true, and irrational (or hypocritical?) to believe what you know to be false. But can it be positively valued to believe what you know to be false (a crossover case)? Or, could it be wise to refuse to face reality and disbelieve what you know 
to be true? What would not be an example of what we are looking for is when you say " $S$ is $P$ is false" but act as it you believe it is true, where your saying is actually a lie. This is not even hypocrisy. Then there is this case: We know that $S$ is $P$ is false, but we want it to be true. Our desire may lead us to "forget" that we know it is false. But this is self-deception and seems not to be praiseworthy.

A good crossover case may be where one knows that $S$ is $P$ is false from a correspondence point of view and does not doubt that, but, nonetheless believes that $\mathrm{S}$ is $\mathrm{P}$ because doing so brings positive value to their life ${ }^{7}$. This does not need to be "refusing to face reality", which would seem to call for negative evaluation. One could very well disbelieve that certain statements correspond with reality, but nonetheless give one's assent to them in another sense. Could it not be a positive thing for a person to live their life as if certain things about themselves or their situation were not true? Here "assent" amounts to conducting oneself according to certain ideas that one does not believe are true in the correspondence sense.

Again, I let the reader take over from here and explore the possibilities and the advantages of the schema.

7 This is like the concept of pragmatic truth. 